\title{
The Logic of Developing Neocortical Circuits in Health and Disease
}

\author{
${ }^{\circledR}$ Ileana L. Hanganu-Opatz, ${ }^{1}{ }^{\circledR}$ Simon J. B. Butt, ${ }^{2}{ }^{\circledR}$ Simon Hippenmeyer, ${ }^{3}{ }^{\circledR}$ Natalia V. De Marco García, ${ }^{4}$ \\ Jessica A. Cardin, ${ }^{5}{ }^{\circledR}$ Bradley Voytek, ${ }^{6,7}$ and ${ }^{\circledR}$ Alysson R. Muotri ${ }^{7,8}$ \\ ${ }^{1}$ Institute of Developmental Neurophysiology, Center for Molecular Neurobiology, University Medical Center Hamburg-Eppendorf, Hamburg, \\ 20246, Germany, ${ }^{2}$ Department of Physiology, Anatomy \& Genetics, University of Oxford, Oxford, OX1 3PT, United Kingdom, ${ }^{3}$ Institute of Science \\ and Technology Austria, Klosterneuburg, 3400, Austria, ${ }^{4}$ Center for Neurogenetics, Brain and Mind Research Institute, Weill Cornell Medicine, \\ New York, New York 10021, ${ }^{5}$ Department of Neuroscience and Kavli Institute for Neuroscience, Yale University, New Haven, Connecticut 06520, \\ ${ }^{6}$ University of California San Diego, Department of Cognitive Science, Halıcıoğlu Data Science Institute, Neurosciences Graduate Program, La Jolla, \\ California 92093, ${ }^{7}$ University of California San Diego, Kavli Institute for Brain and Mind, La Jolla, California 92093, and ${ }^{8}$ University of California \\ San Diego, School of Medicine, Department of Pediatrics/Rady Children's Hospital San Diego, Department of Cellular \& Molecular Medicine, \\ Center for Academic Research and Training in Anthropogeny, La Jolla, California 92037
}

The sensory and cognitive abilities of the mammalian neocortex are underpinned by intricate columnar and laminar circuits formed from an array of diverse neuronal populations. One approach to determining how interactions between these circuit components give rise to complex behavior is to investigate the rules by which cortical circuits are formed and acquire functionality during development. This review summarizes recent research on the development of the neocortex, from genetic determination in neural stem cells through to the dynamic role that specific neuronal populations play in the earliest circuits of neocortex, and how they contribute to emergent function and cognition. While many of these endeavors take advantage of model systems, consideration will also be given to advances in our understanding of activity in nascent human circuits. Such cross-species perspective is imperative when investigating the mechanisms underlying the dysfunction of early neocortical circuits in neurodevelopmental disorders, so that one can identify targets amenable to therapeutic intervention.

Key words: brain organoids; development; neuronal networks; oscillations; sensory cortices; prefrontal cortex

\section{Introduction}

The mammalian cerebral cortex is made up of billions of neurons. In our endeavor to understand normal function and, conversely, dysfunction of this region of the CNS, researchers have documented and probed distinct properties of the

\footnotetext{
Received June 30, 2020; revised Dec. 15, 2020; accepted Dec. 17, 2020.

†I.L.H.-O., S.J.B.B., S.H., N.V.D.M.G., J.A.C., B.V., and A.R.M. contributed equally to this work.

Work in the I.L.H.-0. laboratory was supported by European Research Council Grant ERC-2015-CoG 681577 and German Research Foundation Ha 4466/10-1, Ha4466/11-1, Ha4466/12-1, SPP 1665, and SFB 936B5. Work in the S.J.B.B. laboratory was supported by Biotechnology and Biological Sciences Research Council BB/ P003796/1, Medical Research Council MR/K004387/1 and MR/T033320/1, Wellcome Trust 215199/Z/19/Z and 102386/Z/13/Z, and John Fell Fund. Work in the S.H. laboratory was supported by European Research Council Grants ERC-2016-CoG 725780 LinPro and FWF SFB F78. This work was supported by National Institutes of Health Grant NIMH 1R01MH110553 to N.V.D.M.G. Work in the J.A.C. laboratory was supported by the Ludwig Family Foundation, Simons Foundation SFARI Research Award, and National Institutes of Health/National Institute of Mental Health R01 MH102365 and R01MH113852. The B.V. laboratory was supported by Whitehall Foundation 2017-12-73, National Science Foundation 1736028, National Institutes of Health, National Institute of General Medical Sciences R01GM134363-01, and Halıcıoğlu Data Science Institute Fellowship. This work was supported by the University of California San Diego School of Medicine.

A.R.M. is a co-founder and has equity interest in TISMO0, a company dedicated to genetic analysis and brain organoid modeling focusing on therapeutic applications customized for autism spectrum disorder and other neurological disorders with genetic origins. The terms of this arrangement have been reviewed and approved by the University of California San Diego in accordance with its conflict of interest policies. The remaining authors declare no competing financial interests.

Correspondence should be addressed to Ileana L. Hanganu-Opatz at hangop@zmnh.uni-hamburg.de or Simon J. B. Butt at simon.butt@dpag.ox.ac.uk.

https://doi.org/10.1523/JNEUROSCI.1655-20.2020

Copyright $\odot 2021$ the authors.
}

constituent neurons, such as morphology, patterns of local and long-range connectivity, gene expression, and intrinsic physiology. Understanding how these neurons acquire their identities and form circuits during development is likely to provide insight not only into how these circuits function, but also how they malfunction in various neurological conditions.

The cortex is made up by two major neuronal classes: excitatory projection neurons (representing $\sim 80 \%$ of all cortical neurons) and inhibitory interneurons $(\sim 20 \%)$ (Fishell and Rudy, 2011; Harris and Shepherd, 2015; Lodato and Arlotta, 2015). The development and assembly of cortical circuits is a highly regulated process. In brief, during early embryonic development, excitatory projection neurons are born from neural stem cells (NSCs) in the dorsally located neuroepithelium, while inhibitory interneurons emerge from the ventrally located ganglionic eminences (Lim et al., 2018). Nascent projection neurons migrate radially from the ventricular zone toward the pia to sequentially (i.e., inside-out) build up the distinct cortical layers (Silva et al., 2019). Inhibitory interneurons, on the other hand, migrate tangentially from their place of origin in the ventral forebrain to reach the emerging cortical plate (Fishell and Rudy, 2011; Lim et al., 2018; Silva et al., 2019). Once at the correct target site, migrating inhibitory neurons enter the cortical plate to form local connections with excitatory projection neurons. According to the complex connectivity rules enacted during development, these classes and 
subclasses of neurons are interconnected into cortical circuits, where synaptic inputs are integrated to produce appropriate outputs. The resulting balance between excitation and inhibition (E/I balance) is thought to be critical for physiological cortical circuit function.

Neocortical circuits are capable of dynamically changing throughout life, yet maintaining a fine-tuned balance between stability and plasticity. How neurons assemble into circuits that encode inputs, representations, behavioral states, and actions is still poorly understood. Advances in technologies to monitor, control, and manipulate early neuronal activity have only recently enabled researchers to dissect the contribution of distinct neuronal populations to the functional wiring during development and, consequently, to nascent behavior across species. Because of these advances in the last few years, many of the key questions can now be addressed. For instance, how does cortical cell-type diversity emerge during embryonic development and how does cell-type diversity contribute to the physiology of nascent circuits? What are the mechanisms that ensure and govern the formation of interwoven excitatory and inhibitory circuits and E/I balance during neocortical development? Are these mechanisms general for all neocortical areas or do they differ in relationship to the function/inputs? How do the early patterns of coordinated activity in neocortical areas map onto cortical topography? How does E/I imbalance during development result in life-long miswiring and dysfunction? While most insights originate from rodent models, which are highly amenable to early investigation and genetic interventions, recent advances in human induced pluripotent stem cells (hiPSCs) have the potential to bridge the gaps in our knowledge and help resolve the mechanisms necessary for human brain development in utero.

In this article, we review evidence that has accumulated during the last few years regarding the dynamic role of neuronal populations in the development of functional neocortical ensembles, with particular emphasis on the cellular hubs of diseaserelated miswiring. First, we review recent data on how highly diverse populations of projection neurons emerge. Second, we extract the principles of connectivity development and circuit function as assessed by early patterns of electrical activity (e.g., network oscillations). For this, we focus on the whisker barrel cortex, arguably the best understood developing sensory cortical area in rodents, before switching to prefrontal cortex (PFC), the core of limbic circuitry underlying higher cognitive abilities. Third, we discuss how deviations from these principles cause aberrant network activity and disease-relevant dysfunction. Finally, we introduce pioneering work that aims to translate our understanding in rodents to human brain development, which has, over the centuries, been less accessible to research.

\section{Generating cellular diversity in the developing cerebral cortex}

The cerebral cortex is composed of an extraordinary number of neurons and glial cells. Recent work has highlighted a remarkable heterogeneity in pyramidal cells and interneurons (Ecker et al., 2017; Lein et al., 2017; Zeng and Sanes, 2017). In this section, we mainly focus on principles driving the generation of the former, which are projection neurons (i.e., they often send their axons for long distances), but we refer the reader to a number of recent reviews discussing interneuron heterogeneity (Wamsley and Fishell, 2017; Lim et al., 2018).

The cerebral cortex emerges from neuroepithelial stem cells, which initially amplify their pool but then transform into radial glial progenitor (RGP) cells. RGPs are the major neural progenitors in the developing cortex and their division dynamics along temporal lineage progression determine the final number of neurons in the mature cortex (Taverna et al., 2014; Lodato and Arlotta, 2015; Beattie and Hippenmeyer, 2017). The developmental programs controlling projection neuron genesis need to be precisely implemented and regulated. Impairments in NSC proliferation lead to alterations in the cortical cytoarchitecture, which is thought to be an underlying cause of neurologic diseases (Barkovich et al., 2015; Silbereis et al., 2016).

NSCs differ from most other stem cell niches in that they are required to create a huge variety of distinct neuronal subtypes in a temporally and spatially controlled manner. While the definition of the complete extent of cellular diversity awaits deeper sequencing, recent efforts using single-cell RNA sequencing have started to establish a comprehensive cell atlas of the cerebral cortex (Rosenberg et al., 2018; Saunders et al., 2018; Zeisel et al., 2018). To produce this diversity, NSCs undergo temporal changes across multiple time scales. Within hours, they can react to extrinsic signals, which change their fate in a concentrationand time-dependent manner. Within days, they pass through distinct intrinsic temporal identities to generate different neuronal subtypes over time (Telley et al., 2019).

Although major efforts in the past have established a rough framework describing NSC lineage progression and the generation of cortical cell-type diversity, the precise cellular and molecular mechanisms that underlie this process are still mostly unknown (Holguera and Desplan, 2018). What is the quantitative and qualitative output of a single cortical NSC and how is the output potential modulated during development, across evolution, and in disease? Which genetic, epigenetic, and nichederived factors regulate cortical stem cell lineage progression? And on a more general level, how do progenitor stem cells instruct the overall fate of distinct lineages, which may on their part contribute locally to establish specificity of neuronal connectivity in defined cortical circuits?

To approach the above fundamental questions, lineage tracing in combination with genetic manipulations can provide conceptual and mechanistic insights. A unique strategy enabling the analysis of NSC lineage progression is Mosaic Analysis with Double Markers (MADM) technology (Zong et al., 2005; Contreras et al., 2020). MADM offers a genetic approach to visualize and concomitantly genetically manipulate single clones and small subsets neurons, and it provides single-cell resolution of progenitor division patterns and potential in vivo. Recent MADM-clonal analysis suggests a deterministic nature of RGP behavior (Gao et al., 2014; Beattie et al., 2017) (Fig. 1A). RGPs initially undergo symmetric divisions, which increase the RGP population, then switch to asymmetric divisions, which produce one committed neuron and one RGP. The neurogenic potential of individual RGPs, as they switch from symmetric proliferative division to asymmetric neurogenic division, is fixed, with a unitary output of $\sim 8$ or 9 neurons per individual RGP (Fig. 1A). Upon completion of neurogenesis, a defined fraction of individual RGPs proceed to gliogenesis in which $\sim 1$ in 6 neurogenic RGPs produces glia. Interestingly, while the unitary RGP output is fixed, the laminar distribution of projection neurons within a single clone can vary significantly. While $\sim 50 \%$ of clones include projection neurons in all cortical layers, the other $50 \%$ display more heterogeneous distribution patterns (Llorca et al., 2019). These findings raise the question of whether clonal diversity relates to functional properties in 

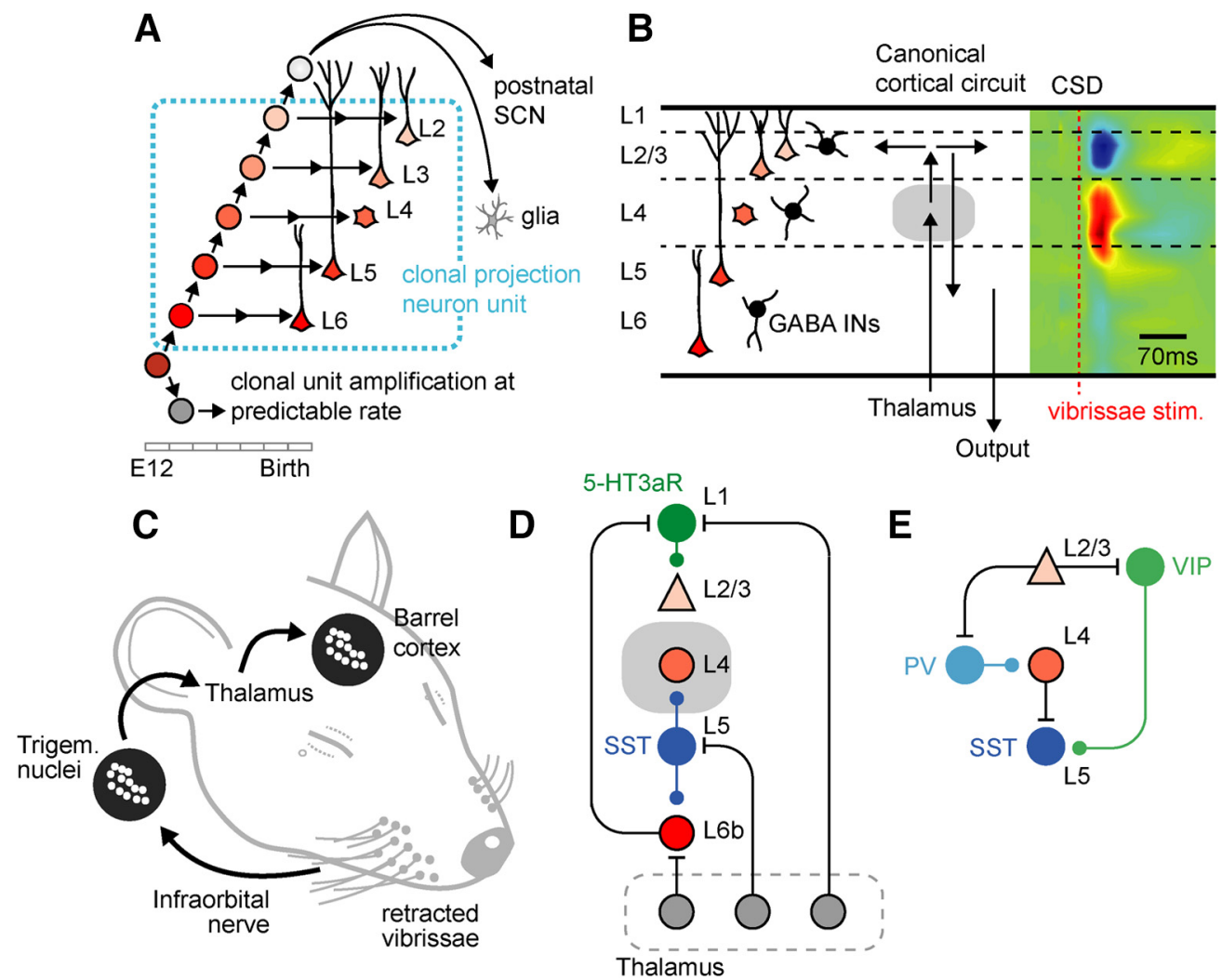

Figure 1. Developing circuits of neocortex. A, A model for NSC lineage progression based on MADM-based lineage tracing experiments. RGPs initially undergo symmetric amplification divisions. The neurogenic potential of individual RGPS, as they switch from symmetric proliferative division to asymmetric neurogenic division, is overall predictable with an output of $\sim 8-9$ neurons per individual RGP (light blue dotted box). Upon completion of neurogenesis, a defined fraction of individual RGPs proceed to gliogenesis, whereby $\sim 1$ in 6 neurogenic RGPs maintains the potential to produce glia, and establishing the postnatal SCN. E12, Embryonic day 12; L2-L6, layers of neocortex; SCN, stem cell niche. B, NSC-derived pyramidal cells (shaded red) and local GABAergic interneurons (INs, black) populate the layers of primary sensory neocortex to give rise to the canonical cortical circuit (middle) that underpins sensory information transfer from thalamic input, which arrives predominantly in layer 4 (L4), and onward transmission to L2/3 and output layers. CSD, Current source density plot showing prominent recruitment of L4 neuron of neonatal somatosensory cortex following stimulation of the vibrissae. C, Topographic representation of the vibrissae is established across the full extent of the whisker somatosensory system within the first postnatal week, at a time when the vibrissae whiskers are retracted. S1BF, Primary somatosensory whisker barrel field. D, During the first postnatal week, L5 and L1 interneurons contribute to sensory-evoked activity to coordinate circuit maturation. 5-HT3aR, Interneurons defined by their expression of the 5-HT3a receptor. $\boldsymbol{E}$, At the same time, other GABAergic interneurons contribute to spontaneous activity to ensure the development of appropriate $E / l$ balance. $\boldsymbol{D}, \boldsymbol{E}$, Color coding of glutamatergic neurons is the same as in $\boldsymbol{A}, \boldsymbol{B}$.

cortical microcircuits (Fig. 1B). In this regard, subtle quantitative differences in clonal architecture could be physiologically relevant (Fang and Yuste, 2017). Based on the above foundations, it will be important in the future to determine the precise role of cell lineage in the assembly of cortical microcircuits (Li et al., 2012; Ohtsuki et al., 2012; Yu et al., 2012; Maruoka et al., 2017) and how cell-type diversity at the single-cell transcriptome level affects physiological properties in canonical cortical microcircuits (Cadwell et al., 2020) (Fig. 1B).

\section{Wiring of cortical circuits and emergence of oscillatory activity: lessons from sensory cortices}

Once generated, the highly diverse cortical neurons densely connect with each other, forming circuits. One of the key steps in the assembly of the canonical cortical circuit is the emergence of coordinated excitatory and inhibitory activity, mediated by pyramidal cells and local GABAergic interneurons, respectively, to enable efficient information processing throughout life (Froemke, 2015; Maffei, et al., 2017). This is made even more challenging by the fact that pyramidal cells and GABAergic interneurons arise from distinct neurogenic niches (Greig et al., 2013; Marin and Muller, 2014; Wamsley and Fishell, 2017). Assembly of the earliest circuits of neocortex is thus dependent on numerous molecular mechanisms that regulate the migration and integration of these cell types in the developing cortical plate (see previous section) throughout early life (Kriegstein and Noctor, 2004; Jabaudon, 2017). Once neurons reach their destination, they begin to establish synapses to form circuits; these early steps are guided by interactions between genetically defined molecular programs and neural activity driven by sensory input.

To date, fundamental research using genetically modified mice has largely focused on the circuits that underpin emergent perception in primary sensory areas because these are malleable to external influences and can readily be used to dissect the contribution of genetics and environment to development. The rodent somatosensory system in particular has been used as a model for circuit assembly (Fig. 1). The diversity of neuronal components and broad timeline for the maturation of the cortical circuit in this area are well understood (Erzurumlu and Gaspar, 2012; Yang et al., 2018). One of the key reasons for this is the prominent relationship between the whisker receptive fields in the periphery and the topographic representations of the vibrissae at every stage of the subsequent sensory pathway from the brainstem to the thalamus, and ultimately in the barrel cortex (Petersen, 2007) (Fig. 1C). This topography develops during early development through the interplay of genetic programs and neuronal activity.

Initial studies in rodents revealed that the barrel cortex displays patterned activity in vivo well before the onset of active 
whisking in the second postnatal week. Spontaneous oscillations, termed spindle bursts, are observed even in the absence of thalamic afferents (Garaschuk et al., 2000; Dupont et al., 2006; Lischalk et al., 2009), suggesting an intracortical origin. However, accumulating experimental evidence indicates that the sensory thalamus is spontaneously active at embryonic stages, and decreasing the excitability of thalamic neurons from embryogenesis onwards leads to an expansion in barrel columns during the first postnatal week (Antón-Bolaños et al., 2019). Recent findings indicate that wavelike activity can originate in the thalamus itself during late embryonic development (Antón-Bolaños et al., 2019), but it can also originate in the whisker pad from spontaneous whisker movements and passive interactions of pups with littermates in the nest (Yang et al., 2009; Akhmetshina et al., 2016; Dooley et al., 2020) (Fig. 1B). Regardless, the data indicate that thalamic inputs are fundamental for restricting the spread of cortical activity and for the emergence of functional topography in the somatosensory cortex. However, it is unclear whether sensory-evoked activity involves the same cortical circuits as those underlying spontaneous oscillations. Further exploration of these circuits, in line with other fields in neuroscience, should make every effort to be aware of behavioral state. To date, most studies have been performed under anesthesia with the recognition that the behavioral repertoire of neonates is limited, and largely dominated by active sleep (Seelke and Blumberg, 2010). However, it is increasingly apparent that differences are observed in nascent cortical activity according to the sleep-wake cycle (Del RioBermudez et al., 2020; Dooley et al., 2020), with active sleep state providing an ideal environment for sensory signaling.

Behavioral state aside, one key question regarding the patterns of coordinated activity in the developing sensory cortices is how they map onto specific cell types. In vivo calcium imaging in combination with genetic strategies has allowed the longitudinal tracking of activity patterns in defined populations of GABAergic interneurons and pyramidal neurons. Although the majority of interneuron classes and pyramidal neurons are spontaneously active toward the end of the first postnatal week, coactivation and participation in network events greatly differ among subtypes (Che et al., 2018) (Fig. 1D,E). For example, interneurons derived from the caudal ganglionic eminence, including both vasoactive intestinal peptide (VIP) and layer 1 (L1) interneurons, exhibit infrequent spontaneous activity. Moreover, although L1 interneurons show low-frequency spontaneous activation at the single-cell level, these calcium-mediated events are widespread and highly synchronous. In contrast, VIP interneurons show limited correlated activity at these early stages. The broad recruitment of caudal ganglionic eminence-derived L1 interneurons is in stark contrast to the topographic activation of interneurons derived from the medial ganglionic eminence. Subsets of medial ganglionic eminence-derived interneurons, including parvalbumin (PV) and somatostatin (SST)-expressing INs, as well as pyramidal neurons are organized in spatially and functionally segregated clusters, or assemblies (Duan et al., 2020; Modol et al., 2020). Synchronous activity within these assemblies protects interneurons from apoptosis, contributing to the emergence of a balanced ratio of excitatory to inhibitory neurons (Duan et al., 2020). Assembly organization in the first postnatal week is most prominent among interneurons that innervate perisomatic regions of pyramidal cells, consistent with the early role for these cells in circuit development (Anastasiades et al., 2016; Modol et al., 2020). Such an arrangement is not found in supragranular SST and L1 interneurons, which display minimal assembly organization at these stages.
In addition to exhibiting spontaneous activity, interneuron subtypes are recruited differentially by sensory inputs (Fig. 1). During the first postnatal week, these inputs efficiently recruit both infragranular SST (Marques-Smith et al., 2016; Tuncdemir et al., 2016) and L1 interneurons (Fig. 1D), the latter through the activation of NR2B-containing NMDA receptors (De Marco Garcia et al., 2015; Che et al., 2018). Sensory-driven activation of L1 interneurons is fundamental for the restriction of ongoing pyramidal cell activity and the sharpening of barrel fields. Decoupling of L1 interneurons from the thalamus leads to enlarged barrels in L4 and long-lasting defects in sensory discrimination (Che et al., 2018). Thus, direct and indirect (Ghezzi et al., 2020) thalamic innervation of superficial interneurons provides an inhibitory gating mechanism to refine sensory maps (Fig. 1D). In contrast, sensory inputs to supragranular fast-spiking interneurons and pyramidal cells are not prominent in the first postnatal week (Bender et al., 2003; Daw et al., 2007). In agreement with these observations, sensory deprivation does not affect pyramidal cell synchronization, and whisker stimulation fails to recruit perisomatic-innervating interneurons at postnatal days 7-9 (Golshani et al., 2009; Che et al., 2018; Modol et al., 2020). Thus, some interneurons and pyramidal cells show functional topography during spontaneous activity, whereas others are recruited by whisker stimulation during development. However, it is unclear how these patterns regulate the fidelity of interneuron-pyramidal cell connectivity to shape barrel column organization throughout cortical layers.

Across early development, GABAergic innervation of pyramidal cells in somatosensory cortex is largely confined to the layer in which the pyramidal cell is located with one prominent exception: translaminar efferent synaptic connections from L5 interneurons that transiently innervate the subplate/L6b (Ghezzi et al., 2020), then L4 (Marques-Smith et al., 2016) (Fig. 1D), before targeting pyramidal cells in L2/3 before the onset of active whisking (Anastasiades et al., 2016). It has been proposed that SST interneurons are the main contributors to this transient, sequential translaminar innervation of cortical layers. This is consistent with the role of this subtype in local circuit development and synaptogenesis (Dupont et al., 2006; Oh, 2016; Tuncdemir et al., 2016). Moreover, SST interneurons originate early during neurogenesis and preferentially populate infragranular layers and thus are ideally suited to direct inside-out formation (i.e., deep layers before superficial layers) of the mammalian neocortex (Butt et al., 2005). Silencing GABAergic transmission from SST interneurons during the first postnatal week reduces the occurrence of spontaneous spindle bursts and associated multiunit activity in vivo (Baruchin and S.J.B.B., unpublished data) consistent with delayed thalamic innervation of L4 spiny stellate neurons observed in vitro (Marques-Smith et al., 2016). Such silencing also affects the response to sensory stimulation; this does not occur when VIP interneurons are silenced.

Despite the apparent importance of SST neurons in the development of thalamocortical innervation in the barrel cortex, it is wrong to think that any particular neuronal subtype has a privileged role in early development. Indeed, recent endeavors have highlighted the contribution of other GABAergic interneurons to circuit maturation and plasticity. These include VIP interneurons (Miyoshi et al., 2010; Miyoshi and Fishell, 2011), which are generated at later embryonic ages. As such, it is somewhat surprising that VIP interneurons contribute to the earliest neonatal circuits, forming synaptic connections onto both infragranular medial ganglionic eminence-derived interneurons and pyramidal cells within the first postnatal week, during the critical period for 


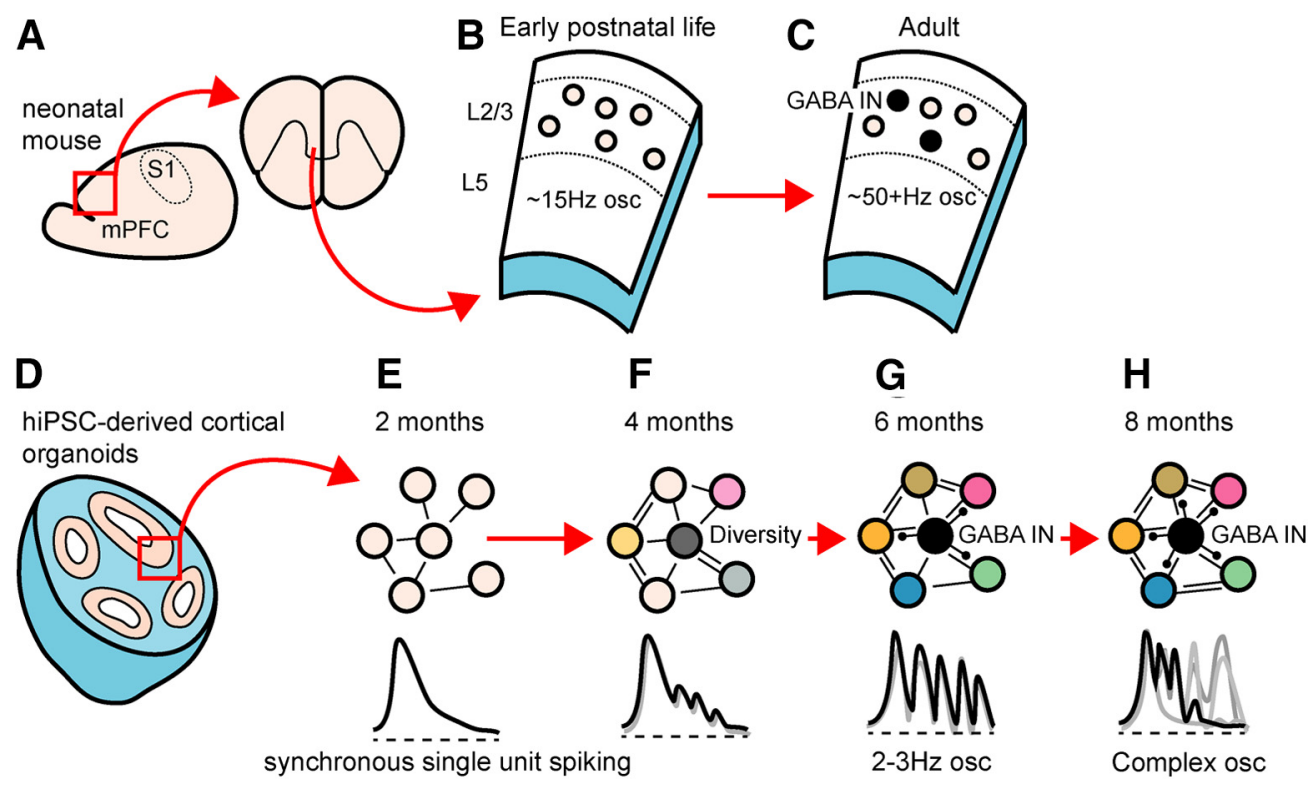

Figure 2. Early oscillations as a hallmark of an emerging network. $A$, Schematic showing the location of $\mathrm{mPFC}$ in the neonatal rodent brain. $B$, Early oscillations (osc) in L2/3 pyramidal cells include transient bouts of $\beta$-low $\gamma(\sim 15 \mathrm{~Hz})$ rhythmic oscillations. C, Development of GABAergic interneurons parallels the emergence of higher-frequency oscillations. D, Brain organoids derived from hiPSCs provide a model system for exploring early rhythmic oscillations in human networks. $E$, At 2 months, synchronous single-unit spiking is observed. This gradually becomes more complex $(\boldsymbol{F})$, such that at $\sim 6$ months $(\boldsymbol{G}) 2-3 \mathrm{~Hz}$ oscillations are observed, followed by $(\boldsymbol{H})$ complex oscillations with the emergence of GABAergic signaling.

plasticity in L4 (Vagnoni et al., 2020) (Fig. 1E). Furthermore, the soma location of these cells in supragranular layers and their early synaptic interaction with the infragranular neuronal types (Fig. 1D,E) identifies the presence of a GABAergic network that spans the depth of neonatal cortex, providing a template for circuit development.

\section{Wiring of cortical circuits and emergence of oscillatory activity: lessons from PFC}

The rodent barrel cortex is a highly specialized, topographically organized columnar circuit. This raises the question of whether the wiring scheme described across development for this sensory cortex applies to other neocortical areas. Of particular interest to our understanding of the mechanisms of neurodevelopment disorders is the mPFC (Fig. 2A). The rodent PFC, despite the lack of structural homology, has certain functional homology with the primate and human prefrontal areas (Carlén, 2017; Chini and Hanganu-Opatz, 2020). In mammals, the PFC is considered the core brain circuitry for complex cognitive processing. Knowledge of how distinct types of prefrontal neurons organize into early circuits and generate early patterns of activity is more limited than our understanding of developing sensory circuits. But some information about PFC development has been acquired by monitoring prefrontal activity at neonatal age during sleep and sleep-like conditions mimicked by some anesthetics (Chini et al., 2020). Discontinuous theta $(4-12 \mathrm{~Hz})$ discharges and transient bouts of $\beta$-low $\gamma$ (12$20 \mathrm{~Hz}$ ) rhythmic oscillations, an early prefrontal activity signature with important functional correlates (Brockmann et al., 2011; Bitzenhofer et al., 2017b; Chini et al., 2020), have been detected. This fast activity relies on pyramidal cells residing within prefrontal L2/3 (Bitzenhofer et al., 2020a, 2020b; Chini et al., 2020) that are boosted by excitatory drive from the hippocampus (Ahlbeck et al., 2018) (Fig. 2B). This oscillatory motif persists and smoothly evolves from the first postnatal week through adulthood, gradually becoming longer, faster (the average frequency increases from $\sim 15 \mathrm{~Hz}$ up to $\sim 50 \mathrm{~Hz}$ ), and of higher amplitude (Bitzenhofer et al., 2020a). These activity changes parallel the unfolding of inhibitory feedback and alterations in inhibition dynamics (Fig. 2C). It is conceivable that inhibition shifts from an early environment in which SST interneurons dominate the GABAergic landscape, to one in which PV-expressing interneurons progressively gain relevance, as previously shown in the barrel field (Marques-Smith et al., 2016; Tuncdemir et al., 2016). Indeed, across the first three postnatal weeks, the strength of SST to pyramidal cell synapses decreases, whereas the opposite occurs for PV interneurons. Of note, early bouts of $\beta-\gamma$ activity are also present in the rodent barrel (Minlebaev et al., 2011; Yang et al., 2013) and visual cortices (Hanganu et al., 2006; Colonnese et al., 2010), yet distinct mechanisms underlie their generation.

\section{Developmental miswiring as disease substrate}

Understanding how circuits comprised of excitatory, glutamatergic pyramidal cells and locally projecting, inhibitory GABAergic interneurons come online across the layers of neocortex is the prerequisite for identifying the key points, both in space and time, that are particularly vulnerable to perturbations. Severe pathologies with high clinical incidence have been proposed to result from developmental disturbance of synaptic connectivity and $\mathrm{E} / \mathrm{I}$ imbalance.

In several developmental mouse models of mental disorders, $\beta-\gamma$ prefrontal oscillations are impaired from the first few postnatal days until adulthood (Xu et al., 2019; Chini et al., 2020; Xu et al., 2020). Severely simplified dendritic arborization, as well as decreased spine density and firing rate of L2/3 pyramidal cells underlie these abnormalities. Investigation of the upstream mechanisms of these deficits highlighted a third cell type, in addition to pyramidal cells and interneurons, with critical relevance for shaping the developing circuits. Microglia, the professional phagocytes of the brain, control the developmental elimination of excess synaptic connections, in a process called synaptic pruning. But excessive pruning as result of hyperactive microglia has been identified as the source of structural and 
functional deficits in neonatal mouse models of mental disorders (Chini et al., 2020; Comer et al., 2020). It is therefore tempting to speculate that the interplay between activity and microglial phagocytosis might be one of the mechanisms through which early activity sculpts developing prefrontal circuits (Hughes and Appel, 2020).

Reduced activity of L2/3 pyramidal cell during development is deleterious, but the opposite effect is equally detrimental. For instance, a protracted but subtle increase of L2/3 pyramidal cell firing across the first two postnatal weeks results in long-term prefrontal microcircuit disruption and E/I imbalance that worsens over time (Bitzenhofer et al., 2020b). Similar deficits have also been described in mouse models of autism spectrum disorder, which are characterized by increased prefrontal activity (Richter et al., 2019; Medendorp, 2020).

Abnormal development of neocortical inhibitory neurons is also relevant to disease. Recent work suggests that the impact of developmental perturbations in GABAergic interneurons stems from their dense connectivity with both pyramidal cell and other GABAergic interneuron populations (Cardin, 2018). GABAergic inhibition plays key roles in regulating postnatal cortical plasticity by controlling the timing and extent of critical period plasticity in cortical circuits (Hensch et al., 1998; Fagiolini and Hensch, 2000). Inhibitory synaptic plasticity can also constrain plasticity at excitatory synapses during the initial postnatal period (L. Wang and Maffei, 2014). In rodent models, the first few postnatal weeks are thus a key period during which modest perturbations of synaptic inhibition have devastating long-term consequences for mature cortical circuit function. Indeed, abnormal development of excitatory pyramidal cell and altered pyramidal cell-pyramidal cell connectivity have been identified as consequences of inhibitory dysregulation in several neurodevelopmental disorders, including autism spectrum disorder and schizophrenia. Disruption of GABAergic signaling through altered firing of interneurons, loss of GABAergic synapses, or loss of GABAergic interneurons themselves leads to circuitlevel disruption of pyramidal cells and activity levels.

Loss of key signaling pathways for GABAergic interneuron development, such as the Nrg1/ErbB4 pathway, leads to disruption of synaptic connectivity between inhibitory and excitatory neurons, increased pyramidal cell firing rates, and abnormal cortical activity patterns (Fazzari et al., 2010; Wen et al., 2010; Del Pino et al., 2013; Marques-Smith et al., 2016) as well as disruption of long-range functional connectivity (Tan et al., 2019). Likewise, the developmental loss of $M e C P 2$ from GABAergic interneurons alters local circuit connectivity, elevates cortical firing rates, disrupts patterns of cortical oscillatory activity, and causes seizures (Chao et al., 2010; Ito-Ishida et al., 2015; Mossner et al., 2020). Furthermore, several studies have found that loss-of-function mutations in the gene for the sodium channel Nav1.1 specifically in interneurons impairs interneuron excitability and leads to disinhibition of pyramidal cells, altered circuit connectivity, and ultimately to seizure (Favero et al., 2018). Ube3a mutations likewise lead to seizure as a result of E/I imbalance (Wallace et al., 2012). Interestingly, long-term alteration of the E/I balance in the adult cortex of genetic models of autism spectrum disorder may partially reflect compensatory changes to offset the impact of developmental perturbation (Antoine et al., 2019).

Although past work has largely focused on the developmental role of the largest population of GABAergic interneurons, the fast spiking, PV-expressing cells, recent evidence indicates a previously unappreciated role for other interneuron populations, the SST-, 5HT3a-, and VIP-expressing cells, in cortical circuit development (Fig. 1D,E). Loss of SST interneurons following Satb1 deletion leads to altered cortical synaptic connectivity and early mortality (Close et al., 2012), further suggesting a critical function for these cells in early life (Marques-Smith et al., 2016; Tuncdemir et al., 2016). Perturbation of layer 1 5HT3aR interneurons by deletion of Lynx1 prevents the development of tonotopy in primary auditory cortex (Takesian et al., 2018). Finally, disruption of early postnatal activity in the sparse VIP interneuron population, because of either ErbB4 or $\mathrm{MeCP} 2$ mutations, causes disinhibition of SST interneurons, loss of behavioral state-dependent cortical regulation, and elevated tonic firing of pyramidal cells, along with disruptions in cortical sensory responsiveness and $\gamma$-band oscillations (Batista-Brito et al., 2017; Mossner et al., 2020). Similar perturbations result from conditional deletion of the transcript factor Proxl in the same population of interneurons (Vagnoni et al., 2020). Together, these findings suggest not only that GABAergic inhibition from multiple sources is critical for experience-dependent fine-tuning of cortical circuits during postnatal maturation, but also that perturbation of these GABAergic circuit components contributes to cortical dysfunction in neurodevelopmental disease.

\section{Human iPSC-derived cortical organoids as a model for neocortical oscillatory circuit development}

Because most of the mechanistic studies addressing developmental wiring have been done in animal models, it is unclear how translatable these observations are to the human brain. Although significant progress has been made in understanding the development of functional brain networks in infants and children, our understanding of human brain development in utero remains largely a mystery. Therefore, hiPSCs have been used to develop brain organoids that mimic early human neurodevelopment at the cellular and molecular levels (Pașca, 2018). Until recently, however, it has been unclear whether these organoids develop functionally dynamic neuronal networks (Trujillo et al., 2019).

One clear hallmark of functioning networks is the presence of neural oscillations (Buzsaki and Draguhn, 2004), which are a ubiquitous signal across brain regions and species (Bullock et al., 2003). Interregional coupling of low-frequency $(<40 \mathrm{~Hz})$ oscillations facilitates information transfer (Varela et al., 2001) and temporal spike synchrony (Fries et al., 1997), whereas faster oscillations are implicated in local circuit processes (Cardin et al., 2009; X. J. Wang, 2010). Neural oscillations are correlated with numerous perceptual, cognitive, and behavioral process (Schnitzler and Gross, 2005); and oscillatory disruptions are similarly widespread, being present in nearly every major neurologic, psychiatric, and developmental disorder (Voytek and Knight, 2015). Yet very little is known about the developmental origins of human neocortical oscillations. Because so many developmental neurocognitive disorders are associated with oscillatory disruptions (Le Van Quyen et al., 2006; Chini et al., 2020), understanding how oscillations develop, and what might disrupt that development during early stages of human embryogenesis, is critical.

Recently, it has been found that hiPSC-derived cortical organoids form small-scale, functional, oscillatory networks (Trujillo et al., 2019) (Fig. 2D-H). Very early in the neural development phase, cortical organoids exhibit highly synchronous single-unit spiking, unlike what is seen in healthy, developed neocortex (Fig. 2E,F). After several months, however, this activity profile spontaneously develops $2-3 \mathrm{~Hz}$ oscillations (Fig. $2 G$ ) that, like oscillations seen in rodent data reviewed above, become more variable in frequency, time, and space with further 
development. This shift toward oscillatory complexity coincides with the development of inhibitory neuronal populations (Fig. $2 \mathrm{H}$ ); blockade of GABAergic signaling does not interfere with overall spiking activity but impairs oscillatory activity. This establishes a causal role for GABA for the maintenance, but not initiation, of oscillations and shows that oscillatory network development is likely dependent on glutamatergic and GABAergic interactions. This is consistent with predominant models for oscillatory generation through $\mathrm{E} / \mathrm{I}$ interactions (Buzsáki and Wang, 2012).

The separation of oscillations into different frequency bands is particularly striking given the important role that multifrequency interactions play in human neural network functioning and cognition (Canolty and Knight, 2010). Specifically, in humans, low-frequency oscillations rhythmically modulate high-frequency $(>100 \mathrm{~Hz})$ activity, a surrogate of population spiking (Mukamel et al., 2005). This phase-amplitude coupling likely plays an important role in human cognition, including working memory (Johnson et al., 2018) and goal maintenance (Voytek et al., 2015). In cortical organoids, similar phaseamplitude coupling was observed: specifically, the phase of $\sim 3 \mathrm{~Hz}$ oscillations was comodulated with the power of high-frequency activity (Trujillo et al., 2019).

Notably, hiPSC-derived cortical organoids appear to recapitulate the electrophysiological developmental trajectory seen in preterm infant EEG. Using a machine-learning model trained to predict human neonatal age from comparable EEG features, the developmental timeline of cortical organoids can be predicted from the presence, absence, and strength of electrophysiological features, including oscillatory power. While the functional equivalence between human neocortex and cortical organoids cannot be proved, these results are encouraging: hiPSC-derived human cortical organoids spontaneously develop neural oscillations that exhibit spatiotemporal complexity, in which low-frequency oscillations interact with high-frequency activity. The development of these complex electrophysiological features mimics what is seen in preterm infant EEG. While these results are far from conclusive, they provide converging lines of evidence that support the use of cortical organoids as a model for studying early human neurodevelopment.

\section{Conclusions and open questions}

Increasing knowledge of the genetic diversity of cortical neurons gives us better access and understanding of early neuronal circuits (Di Bella et al., 2020). However, it will be crucial in future studies to determine how genetic cell-type diversity translates into cellular phenotype and physiological function at the microcircuit level. Although the existence of activity patterns in the neocortex has long been observed, evidence that these patterns dictate emergent connectivity and later function has remained elusive. Accumulating evidence from sensory and limbic cortices indicates that select neuronal populations participate in sensory-evoked and spontaneous network activity and that these activity patterns control specific aspects of early cortical development. Additional research will be needed to further dissect the diversity of neuronal, and particularly GABAergic subtypes, in emergent circuits.

Although RNA sequencing has been instrumental in revealing early subtype identity (Mayer et al., 2018), gaining genetic access to these immature populations remains challenging. This is particularly difficult for fast-spiking interneurons, frequently identified by their PV expression status, which becomes evident only in the second postnatal week (del Rio et al., 1994). Early identity markers, such as Mef2c (Mayer et al., 2018) and Tac1 (Wamsley et al., 2018), hold promise for the intersectional targeting of this population. The respective roles of the distinct populations of GABAergic interneurons in the early postnatal maturation of cortical circuits remain to be fully elucidated. In addition, the impact of synaptic interactions among the different GABAergic populations on cortical maturation has only recently been identified and remains to be explored. It will be important to match activity patterns revealed by calcium imaging to those recorded with microelectrodes in vivo and neurotransmitter uncaging in slices. Going forward, it will be important to determine whether spindle bursts, long oscillations, and $\beta-\gamma$ oscillations entrain different populations of developing cortical neurons in functional ensembles and what role they have in the development of adult circuit function and behavior. Future investigations will bring us closer to the understanding the rules governing cortical development.

\section{References}

Ahlbeck J, Song L, Chini M, Bitzenhofer SH, Hanganu-Opatz IL (2018) Glutamatergic drive along the septo-temporal axis of hippocampus boosts prelimbic oscillations in the neonatal mouse. Elife 7:e33158.

Akhmetshina D, Nasretdinov A, Zakharov A, Valeeva G, Khazipov R (2016) The nature of the sensory input to the neonatal rat barrel cortex. J Neurosci 36:9922-9932.

Anastasiades PG, Marques-Smith A, Lyngholm D, Lickiss T, Raffiq S, Kätzel D, Miesenböck G, Butt SJ (2016) GABAergic interneurons form transient layer-specific circuits in early postnatal neocortex. Nat Commun 7:10584.

Antoine MW, Langberg T, Schnepel P, Feldman DE (2019) Increased excitation-inhibition ratio stabilizes synapse and circuit excitability in four autism mouse models. Neuron 101:648-661.

Antón-Bolaños N, Sempere-Ferràndez A, Guillamón-Vivancos T, Martini FJ, Pérez-Saiz L, Gezelius H, Filipchuk A, Valdeolmillos M, López-Bendito G (2019) Prenatal activity from thalamic neurons governs the emergence of functional cortical maps in mice. Science 364:987-990.

Barkovich AJ, Dobyns WB, Guerrini R (2015) Malformations of cortical development and epilepsy. Cold Spring Harb Perspect Med 5:a022392.

Batista-Brito R, Vinck M, Ferguson KA, Chang JT, Laubender D, Lur G, Mossner JM, Hernandez VG, Ramakrishnan C, Deisseroth K, Higley MJ, Cardin JA (2017) Developmental dysfunction of VIP interneurons impairs cortical circuits. Neuron 95:884-895.

Beattie R, Hippenmeyer S (2017) Mechanisms of radial glia progenitor cell lineage progression. FEBS Lett 591:3993-4008.

Beattie R, Postiglione MP, Burnett LE, Laukoter S, Streicher C, Pauler FM, Xiao G, Klezovitch O, Vasioukhin V, Ghashghaei TH, Hippenmeyer S (2017) Mosaic analysis with double markers reveals distinct sequential functions of Lgl1 in neural stem cells. Neuron 94:517-533.e513.

Bender KJ, Rangel J, Feldman DE (2003) Development of columnar topography in the excitatory layer 4 to layer $2 / 3$ projection in rat barrel cortex. $J$ Neurosci 23:8759-8770.

Bitzenhofer SH, Ahlbeck J, Wolff A, Wiegert JS, Gee CE, Oertner TG, Hanganu-Opatz IL (2017) Layer-specific optogenetic activation of pyramidal neurons causes beta-gamma entrainment of neonatal networks. Nat Commun 8:14563.

Bitzenhofer SH, Pöpplau JA, Hanganu-Opatz IL (2020a) Gamma activity accelerates during prefrontal development. eLife 9:e56795.

Bitzenhofer SH, Pöpplau JA, Chini M, Marquardt A, Hanganu-Opatz IL (2020b) Transient developmental increase of prefrontal activity alters network maturation and causes cognitive dysfunction in adult mice. bioRxiv 558957. doi: https://doi.org/10.1101/558957.

Brockmann MD, Pöschel B, Cichon N, Hanganu-Opatz IL (2011) Coupled oscillations mediate directed interactions between prefrontal cortex and hippocampus of the neonatal rat. Neuron 71:332-347.

Bullock TH, McClune MC, Enright JT (2003) Are the electroencephalograms mainly rhythmic? Assessment of periodicity in wide-band time series. Neuroscience 121:233-252.

Butt SJ, Fuccillo M, Nery S, Noctor S, Kriegstein A, Corbin JG, Fishell G (2005) The temporal and spatial origins of cortical interneurons predict their physiological subtype. Neuron 48:591-604. 
Buzsaki G, Draguhn A (2004) Neuronal oscillations in cortical networks. Science 304:1926-1929.

Buzsáki G, Wang XJ (2012) Mechanisms of gamma oscillations. Annu Rev Neurosci 35:203-225.

Cadwell CR, Scala F, Fahey PG, Kobak D, Mulherkar S, Sinz FH, Papadopoulos S, Tan ZH, Johnsson P, Hartmanis L, Li S, Cotton RJ, Tolias KF, Sandberg R, Berens P, Jiang X, Tolias AS (2020) Cell type composition and circuit organization of clonally related excitatory neurons in the juvenile mouse neocortex. eLife 9:e52951.

Canolty RT, Knight RT (2010) The functional role of cross-frequency coupling. Trends Cogn Sci 14:506-515.

Cardin JA (2018) Inhibitory interneurons regulate temporal precision and correlations in cortical circuits. Trends Neurosci 41:689-700.

Cardin JA, Carlén M, Meletis K, Knoblich U, Zhang F, Deisseroth K, Tsai LH, Moore CI (2009) Driving fast-spiking cells induces gamma rhythm and controls sensory responses. Nature 459:663-667.

Carlén M (2017) What constitutes the prefrontal cortex? Science 358:478482.

Chao HT, Chen H, Samaco RC, Xue M, Chahrour M, Yoo J, Neul JL, Gong S, Lu HC, Heintz N, Ekker M, Rubenstein JL, Noebels JL, Rosenmund C, Zoghbi HY (2010) Dysfunction in GABA signalling mediates autism-like stereotypies and Rett syndrome phenotypes. Nature 468:263-269.

Che A, Babij R, Iannone AF, Fetcho RN, Ferrer M, Liston C, Fishell G, De Marco García NV (2018) Layer I interneurons sharpen sensory maps during neonatal development. Neuron 99:98-116.

Chini M, Hanganu-Opatz IL (2020) Prefrontal cortex development in health and disease: lessons from rodents and humans. Trends Neurosci Advance online publication. Retrieved Nov 24, 2020. doi: 10.1016/j. tins.2020.10.017

Chini M, Pöpplau JA, Lindemann C, Carol-Perdiguer L, Hnida M, Oberländer V, Xu X, Ahlbeck J, Bitzenhofer SH, Mulert C, HanganuOpatz IL (2020) Resolving and rescuing developmental miswiring in a mouse model of cognitive impairment. Neuron 105:60-74.

Close J, Xu H, De Marco García NV, Batista-Brito R, Rossignol E, Rudy B, Fishell G (2012) Satb1 is an activity-modulated transcription factor required for the terminal differentiation and connectivity of medial ganglionic eminence-derived cortical interneurons. J Neurosci 32:1769017705

Colonnese MT, Kaminska A, Minlebaev M, Milh M, Bloem B, Lescure S, Moriette G, Chiron C, Ben-Ari Y, Khazipov R (2010) A conserved switch in sensory processing prepares developing neocortex for vision. Neuron 67:480-498.

Contreras X, Davaatseren A, Amberg N, Hansen AH, Sonntag J, Andersen L, Bernthaler T, Heger A, Johnson R, Schwarz LA, Luo L, Rülicke T, Hippenmeyer S (2020) A genome-wide library of MADM mice for single-cell genetic mosaic analysis. bioRxiv 2020.06.05.136192. doi: https:// doi.org/10.1101/2020.06.05.136192.

Comer AL, Jinadasa T, Sriram B, Phadke RA, Kretsge LN, Nguyen TP, Antognetti G, Gilbert JP, Lee J, Newmark ER, Hausmann FS, Rosenthal S, Liu Kot K, Liu Y, Yen WW, Dejanovic B, Cruz-Martín A (2020) Increased expression of schizophrenia-associated gene $\mathrm{C} 4$ leads to hypoconnectivity of prefrontal cortex and reduced social interaction. PLoS Biol 18:e3000604.

Daw MI, Ashby MC, Isaac JT (2007) Coordinated developmental recruitment of latent fast spiking interneurons in layer IV barrel cortex. Nat Neurosci 10:453-461.

De Marco Garcia NV, Priya R, Tuncdemir SN, Fishell G, Karayannis T (2015) Sensory inputs control the integration of neurogliaform interneurons into cortical circuits. Nat Neurosci 18:393-401.

Del Pino I, García-Frigola C, Dehorter N, Brotons-Mas JR, Alvarez-Salvado E, Martínez de Lagrán M, Ciceri G, Gabaldón MV, Moratal D, Dierssen M, Canals S, Marín O, Rico B (2013) Erbb4 deletion from fast-spiking interneurons causes schizophrenia-like phenotypes. Neuron 79:11521168.

Del Rio-Bermudez C, Kim J, Sokoloff G, Blumberg MS (2020) Active sleep promotes coherent oscillatory activity in the cortico-hippocampal system of infant rats. Cereb Cortex 30:2070-2082.

del Rio JA, de Lecea L, Ferrer I, Soriano E (1994) The development of parvalbumin-immunoreactivity in the neocortex of the mouse. Brain Res Dev Brain Res 81:247-259.

Di Bella DJ, Habibi E, Yang SM, Stickels RR, Brown J, Yadollahpour P, Chen F, Macosko EZ, Regev A, Arlotta P (2020) Molecular logic of cellular diversification in the mammalian cerebral cortex. bioRxiv 2020.07.02.185439. doi: https://doi.org/10.1101/2020.07.02.185439.

Dooley JC, Glanz RM, Sokoloff G, Blumberg MS (2020) Self-generated whisker movements drive state-dependent sensory input to developing barrel cortex. Curr Biol 30:2404-2410.

Duan ZR, Che A, Chu P, Modol L, Bollmann Y, Babij R, Fetcho RN, Otsuka T, Fuccillo MV, Liston C, Pisapia DJ, Cossart R, De Marco García NV (2020) GABAergic restriction of network dynamics regulates interneuron survival in the developing cortex. Neuron 105:75-92.e5.

Dupont E, Hanganu IL, Kilb W, Hirsch S, Luhmann HJ (2006) Rapid developmental switch in the mechanisms driving early cortical columnar networks. Nature 439:79-83.

Ecker JR, Geschwind DH, Kriegstein AR, Ngai J, Osten P, Polioudakis D, Regev A, Sestan N, Wickersham IR, Zeng H (2017) The BRAIN Initiative Cell Census Consortium: lessons learned toward generating a comprehensive brain cell atlas. Neuron 96:542-557.

Erzurumlu RS, Gaspar P (2012) Development and critical period plasticity of the barrel cortex. Eur J Neurosci 35:1540-1553.

Fagiolini M, Hensch TK (2000) Inhibitory threshold for critical-period activation in primary visual cortex. Nature 404:183-186.

Fang WQ, Yuste R (2017) Overproduction of neurons is correlated with enhanced cortical ensembles and increased perceptual discrimination. Cell Rep 21:381-392.

Favero M, Sotuyo NP, Lopez E, Kearney JA, Goldberg EM (2018) A transient developmental window of fast-spiking interneuron dysfunction in a mouse model of Dravet syndrome. J Neurosci 38:7912-7927.

Fazzari P, Paternain AV, Valiente M, Pla R, Luján R, Lloyd K, Lerma J, Marín O, Rico B (2010) Control of cortical GABA circuitry development by Nrg1 and ErbB4 signalling. Nature 464:1376-1380.

Fishell G, Rudy B (2011) Mechanisms of inhibition within the telencephalon: "where the wild things are." Annu Rev Neurosci 34:535-567.

Fries P, Roelfsema PR, Engel AK, Konig P, Singer W (1997) Synchronization of oscillatory responses in visual cortex correlates with perception in interocular rivalry. Proc Natl Acad Sci USA 94:12699-12704.

Froemke RC (2015) Plasticity of cortical excitatory-inhibitory balance. Annu Rev Neurosci 38:195-219.

Gao P, Postiglione MP, Krieger TG, Hernandez L, Wang C, Han Z, Streicher C, Papusheva E, Insolera R, Chugh K, Kodish O, Huang K, Simons BD, Luo L, Hippenmeyer S, Shi SH (2014) Deterministic progenitor behavior and unitary production of neurons in the neocortex. Cell 159:775-788.

Garaschuk O, Linn J, Eilers J, Konnerth A (2000) Large-scale oscillatory calcium waves in the immature cortex. Nat Neurosci 3:452-459.

Ghezzi F, Marques-Smith A, Anastasiades P, Lyngholm D, Vagnoni C, Rowett A, Hoerder-Suabedissen A, Nakagawa Y, Molnár Z, Butt SJ (2020) Non-canonical role for Lparl-EGFP subplate neurons in early postnatal somatosensory cortex. bioRxiv 2020.05.12.088450. doi: https:// doi.org/10.1101/2020.05.12.088450.

Golshani P, Gonçalves JT, Khoshkhoo S, Mostany R, Smirnakis S, PorteraCailliau C (2009) Internally mediated developmental desynchronization of neocortical network activity. J Neurosci 29:10890-10899.

Greig LC, Woodworth MB, Galazo MJ, Padmanabhan H, Macklis JD (2013) Molecular logic of neocortical projection neuron specification, development and diversity. Nat Rev Neurosci 14:755-769.

Harris KD, Shepherd GM (2015) The neocortical circuit: themes and variations. Nat Neurosci 18:170-181.

Hanganu IL, Ben-Ari Y, Khazipov R (2006) Retinal waves trigger spindle bursts in the neonatal rat visual cortex. J Neurosci 26:6728-6736.

Hensch TK, Fagiolini M, Mataga N, Stryker MP, Baekkeskov S, Kash SF (1998) Local GABA circuit control of experience-dependent plasticity in developing visual cortex. Science 282:1504-1508.

Holguera I, Desplan C (2018) Neuronal specification in space and time. Science 362:176-180

Hughes AN, Appel B (2020) Microglia phagocytose myelin sheaths to modify developmental myelination. Nat Neurosci 23:1055-1066.

Ito-Ishida A, Ure K, Chen H, Swann JW, Zoghbi HY (2015) Loss of MeCP2 in parvalbumin- and somatostatin-expressing neurons in mice leads to distinct Rett syndrome-like phenotypes. Neuron 88:651-658.

Jabaudon D (2017) Fate and freedom in developing neocortical circuits. Nat Commun 8:16042.

Johnson EL, Adams JN, Solbakk AK, Endestad T, Larsson PG, Ivanovic J, Meling TR, Lin JJ, Knight RT (2018) Dynamic frontotemporal systems process space and time in working memory. PLoS Biol 16:e2004274 
Kriegstein AR, Noctor SC (2004) Patterns of neuronal migration in the embryonic cortex. Trends Neurosci 27:392-399.

Le Van Quyen M, Khalilov I, Ben-Ari Y (2006) The dark side of high-frequency oscillations in the developing brain. Trends Neurosci 29:419-427.

Lein E, Borm LE, Linnarsson S (2017) The promise of spatial transcriptomics for neuroscience in the era of molecular cell typing. Science 358:64-69.

Li Y, Lu H, Cheng PL, Ge S, Xu H, Shi SH, Dan Y (2012) Clonally related visual cortical neurons show similar stimulus feature selectivity. Nature 486:118-121.

Lim L, Mi D, Llorca A, Marin O (2018) Development and functional diversification of cortical interneurons. Neuron 100:294-313.

Lischalk JW, Easton CR, Moody WJ (2009) Bilaterally propagating waves of spontaneous activity arising from discrete pacemakers in the neonatal mouse cerebral cortex. Dev Neurobiol 69:407-414.

Llorca A, Ciceri G, Beattie R, Wong FK, Diana G, Serafeimidou-Pouliou E, Fernandez-Otero M, Streicher C, Arnold SJ, Meyer M, Hippenmeyer S, Maravall M, Marin O (2019) A stochastic framework of neurogenesis underlies the assembly of neocortical cytoarchitecture. eLife 8:e51381.

Lodato S, Arlotta P (2015) Generating neuronal diversity in the mammalian cerebral cortex. Annu Rev Cell Dev Biol 31:699-720.

Maffei A, Charrier C, Caiati MD, Barberis A, Mahadevan V, Woodin MA, Tyagarajan SK (2017) Emerging mechanisms underlying dynamics of GABAergic synapses. J Neurosci 37:10792-10799.

Marques-Smith A, Lyngholm D, Kaufmann AK, Stacey JA, HoerderSuabedissen A, Becker EB, Wilson MC, Molnár Z, Butt SJ (2016) A transient translaminar GABAergic interneuron circuit connects thalamocortical recipient layers in neonatal somatosensory cortex. Neuron 89:536549.

Marin O, Muller U (2014) Lineage origins of GABAergic versus glutamatergic neurons in the neocortex. Curr Opin Neurobiol 26:132-141.

Maruoka H, Nakagawa N, Tsuruno S, Sakai S, Yoneda T, Hosoya T (2017) Lattice system of functionally distinct cell types in the neocortex. Science 358:610-615.

Mayer C, Hafemeister C, Bandler RC, Machold R, Batista Brito R, Jaglin X, Allaway K, Butler A, Fishell G, Satija R (2018) Developmental diversification of cortical inhibitory interneurons. Nature 555:457-462.

Medendorp WE (2020) Selective postnatal excitation of neocortical pyramidal neurons results in distinctive behavioral and circuit deficits in adulthood. bioRxiv 2020.2001.2018.911347. doi: https://doi.org/10.1101/2020. 01.18.911347.

Minlebaev M, Colonnese M, Tsintsadze T, Sirota A, Khazipov R (2011) Early $\gamma$ oscillations synchronize developing thalamus and cortex. Science 334:226-229.

Miyoshi G, Hjerling-Leffler J, Karayannis T, Sousa VH, Butt SJ, Battiste J, Johnson JE, Machold RP, Fishell G (2010) Genetic fate mapping reveals that the caudal ganglionic eminence produces a large and diverse population of superficial cortical interneurons. J Neurosci 30:1582-1594.

Miyoshi G, Fishell G (2011) GABAergic interneuron lineages selectively sort into specific cortical layers during early postnatal development. Cereb Cortex 21:845-852.

Modol L, Bollmann Y, Tressard T, Baude A, Che A, Duan ZR, Babij R, De Marco García NV, Cossart R (2020) Assemblies of perisomatic GABAergic neurons in the developing barrel cortex. Neuron 105:93-105.

Mossner JM, Batista-Brito R, Pant R, Cardin JA (2020) Developmental loss of $\mathrm{MeCP} 2$ from VIP interneurons impairs cortical function and behavior. Elife 9:e55639.

Mukamel RH, Arieli GA, Hasson U, Fried I, Malach R (2005) Coupling between neuronal firing, field potentials, and fMRI in human auditory cortex. Science 309:951-954.

Oh WC, Lutzu S, Castillo PE, Kwon HB (2016) De novo synaptogenesis induced by GABA in the developing mouse cortex. Science 353:10371040.

Ohtsuki G, Nishiyama M, Yoshida T, Murakami T, Histed M, Lois C, Ohki K (2012) Similarity of visual selectivity among clonally related neurons in visual cortex. Neuron 75:65-72.

Pașca SP (2018) The rise of three-dimensional human brain cultures. Nature 553:437-445.

Petersen CC (2007) The functional organization of the barrel cortex. Neuron 56:339-355

Richter M, Murtaza N, Scharrenberg R, White SH, Johanns O, Walker S, Yuen RK, Schwanke B, Bedürftig B, Henis M, Scharf S, Kraus V, Dörk R, Hellmann J, Lindenmaier Z, Ellegood J, Hartung H, Kwan V, Sedlacik J,
Fiehler J, et al. (2019) Altered TAOK2 activity causes autism-related neurodevelopmental and cognitive abnormalities through RhoA signaling. Mol Psychiatry 24:1329-1350.

Rosenberg AB, Roco CM, Muscat RA, Kuchina A, Sample P, Yao Z, Graybuck LT, Peeler DJ, Mukherjee S, Chen W, Pun SH, Sellers DL, Tasic B, Seelig G (2018) Single-cell profiling of the developing mouse brain and spinal cord with split-pool barcoding. Science 360:176-182.

Saunders A, Macosko EZ, Wysoker A, Goldman M, Krienen FM, de Rivera H, Bien E, Baum M, Bortolin L, Wang S, Goeva A, Nemesh J, Kamitaki N, Brumbaugh S, Kulp D, McCarroll SA (2018) Molecular diversity and specializations among the cells of the adult mouse brain. Cell 174:10151030.e1016.

Schnitzler A, Gross J (2005) Normal and pathological oscillatory communication in the brain. Nat Rev Neurosci 6:285-296.

Seelke AM, Blumberg MS (2010) Developmental appearance and disappearance of cortical events and oscillations in infant rats. Brain Res 1324:34-42.

Silbereis JC, Pochareddy S, Zhu Y, Li M, Sestan N (2016) The cellular and molecular landscapes of the developing human central nervous system. Neuron 89:248-268.

Silva CG, Peyre E, Nguyen L (2019) Cell migration promotes dynamic cellular interactions to control cerebral cortex morphogenesis. Nat Rev Neurosci 20:318-329.

Takesian AE, Bogart LJ, Lichtman JW, Hensch TK (2018) Inhibitory circuit gating of auditory critical-period plasticity. Nat Neurosci 21:218-227.

Tan B, Liu Q, Wan C, Jin Z, Yang Y, Li L (2019) Altered functional connectivity of alpha rhythm in obsessive-compulsive disorder during rest. Clin EEG Neurosci 50:88-99.

Taverna E, Gotz M, Huttner WB (2014) The cell biology of neurogenesis: toward an understanding of the development and evolution of the neocortex. Annu Rev Cell Dev Biol 30:465-502.

Telley L, Agirman G, Prados J, Amberg N, Fievre S, Oberst P, Bartolini G, Vitali I, Cadilhac C, Hippenmeyer S, Nguyen L, Dayer A, Jabaudon D (2019) Temporal patterning of apical progenitors and their daughter neurons in the developing neocortex. Science 364:eaav2522.

Trujillo CA, Gao R, Negraes PD, Gu J, Buchanan J, Preissl S, Wang A, Wu W, Haddad GG, Chaim IA, Domissy A, Vandenberghe M, Devor A, Yeo GW, Voytek B, Muotri AR (2019) Complex oscillatory waves emerging from cortical organoids model early human brain network development. Cell Stem Cell 25:558-569.

Tuncdemir SN, Wamsley B, Stam FJ, Osakada F, Goulding M, Callaway EM, Rudy B, Fishell G (2016) Early somatostatin interneuron connectivity mediates the maturation of deep layer cortical circuits. Neuron 89:521-535.

Vagnoni C, Baruchin LJ, Ghezzi F, Ratti S, Molnár Z, Butt SJ (2020) Ontogeny of the $\mathrm{VIP}^{+}$interneuron sensory-motor circuit prior to active whisking. bioRxiv 2020.07.01.182238. doi: https://doi.org/10.1101/2020. 07.01.182238

Varela F, Lachaux JP, Rodriguez E, Martinerie J (2001) The Brainweb: phase synchronization and large-scale integration. Nat Rev Neurosci 2:229239.

Voytek B, Knight RT (2015) Dynamic network communication as a unifying neural basis for cognition, development, aging, and disease. Biol Psychiatry 77:1089-1097.

Voytek B, Kayser AS, Badre D, Fegen D, Chang EF, Crone NE, Parvizi J, Knight RT, D'Esposito M (2015) Oscillatory dynamics coordinating human frontal networks in support of goal maintenance. Nat Neurosci 18:1318-1324.

Wallace ML, Burette AC, Weinberg RJ, Philpot BD (2012) Maternal loss of Ube3a produces an excitatory/inhibitory imbalance through neuron type-specific synaptic defects. Neuron 74:793-800.

Wamsley B, Fishell G (2017) Genetic and activity-dependent mechanisms underlying interneuron diversity. Nat Rev Neurosci 18:299-309.

Wamsley B, Jaglin XH, Favuzzi E, Quattrocolo G, Nigro MJ, Yusuf N, Khodadadi-Jamayran A, Rudy B, Fishell G (2018) Rbfox1 mediates celltype-specific splicing in cortical interneurons. Neuron 100:846-859.e7.

Wang L, Maffei A (2014) Inhibitory plasticity dictates the sign of plasticity at excitatory synapses. J Neurosci 34:1083-1093.

Wang XJ (2010) Neurophysiological and computational principles of cortical rhythms in cognition. Physiol Rev 90:1195-1268.

Wen L, Lu YS, Zhu XH, Li XM, Woo RS, Chen YJ, Yin DM, Lai C, Terry AV Jr, Vazdarjanova A, Xiong WC, Mei L (2010) Neuregulin 1 regulates pyramidal neuron activity via ErbB4 in parvalbumin-positive interneurons. Proc Natl Acad Sci USA 107:1211-1216. 19 
Xu X, Chini M, Bitzenhofer SH, Hanganu-Opatz IL (2019) Transient knockdown of prefrontal DISC1 in immune-challenged mice causes abnormal long-range coupling and cognitive dysfunction throughout development. J Neurosci 39:1222-1235.

Xu X, Song L, Hanganu-Opatz IL (2020) Knock-down of hippocampal DISC1 in immune-challenged mice impairs the prefrontal-hippocampal coupling and the cognitive performance throughout development. Cereb Cortex Advance online publication. Retrieved Oct 10, 2020. doi: 10.1093/ cercor/bhaa291.

Yang JW, Kilb W, Kirischuk S, Unichenko P, Stüttgen MC, Luhmann HJ (2018) Development of the whisker-to-barrel cortex system. Curr Opin Neurobiol 53:29-34

Yang JW, An S, Sun JJ, Reyes-Puerta V, Kindler J, Berger T, Kilb W, Luhmann HJ (2013) Thalamic network oscillations synchronize ontogenetic columns in the newborn rat barrel cortex. Cereb Cortex 23:1299-1316.
Yang JW, Hanganu-Opatz IL, Sun JJ, Luhmann HJ (2009) Three patterns of oscillatory activity differentially synchronize developing neocortical networks in vivo. J Neurosci 29:9011-9025.

Yu YC, He S, Chen S, Fu Y, Brown KN, Yao XH, Ma J, Gao KP, Sosinsky GE, Huang K, Shi SH (2012) Preferential electrical coupling regulates neocortical lineage-dependent microcircuit assembly. Nature 486:113-117.

Zeisel A, Hochgerner H, Lonnerberg P, Johnsson A, Memic F, van der Zwan J, Haring M, Braun E, Borm LE, La Manno G, Codeluppi S, Furlan A, Lee K, Skene N, Harris KD, Hjerling-Leffler J, Arenas E, Ernfors P, Marklund U, Linnarsson S (2018) Molecular architecture of the mouse nervous system. Cell 174:999-1014.e1022.

Zeng H, Sanes JR (2017) Neuronal cell-type classification: challenges, opportunities and the path forward. Nat Rev Neurosci 18:530-546.

Zong H, Espinosa JS, Su HH, Muzumdar MD, Luo L (2005) Mosaic analysis with double markers in mice. Cell 121:479-492. 